\title{
When climate change encounters the revolution in adult longevity
}

\author{
Jean-Marie Robine ${ }^{1}[$
}

Received: 25 September 2017 / Accepted: 3 October 2017 / Published online: 26 October 2017

(c) Springer International Publishing AG 2017

In this issue Aging Clinical and Experimental Research publishes a short communication by Ugo Fedeli and colleagues on the excess mortality observed in the north of Italy during the winter 2014/2015 and the summer 2015 [1]. While mortality fluctuations were thought to belong to history, large fluctuations are returning rapidly, from one winter to another. Excess mortality struck during the winters 2011/2012,2014/2015, and again during the winter 2016/2017 [2, 3]. The graphs available on the Euro-MOMO (European monitoring of excess mortality for public health action) website, which includes data from 19 European countries, speak for themselves. In France, for example, the number of deaths among those over 80 years of age increased by 23,846 cases in 2012 compared to 2011 and again by 28,095 cases in 2015 compared to 2014. A new surge of mortality is expected in 2017 compared to 2016. This excess of mortality is essentially concentrated during the influenza episodes that occurred in the first months of the years 2012, 2015, and 2017. These episodes are characterized by the predominance of influenza A H3N2 virus which specifically affects the oldest-old population. For the sole winter 2014/2015, the mortality excess among the old population was estimated at 217,000 premature deaths in the European Union, which is considerably more that the death toll of the 2003 European heat wave. Is it Murphy's law or a profound change in the risk structure?

Climate scientists announce that current global warming will cause an upsurge and a worsening of extreme weather events, such as heat waves, flooding and droughts, as well

Jean-Marie Robine

jean-marie.robine@inserm.fr

1 MMDN, Univ. Montpellier, EPHE, INSERM, U1198, PSL Research University, Montpellier 34095, France as winter cold spells. However, several authors consider that modern living conditions have largely disconnected winter mortality from prevailing weather conditions [4]. So, what can explain this return of winter fluctuation in mortality? Answering this question is difficult because the reasons for this excess mortality remains insufficiently analyzed in epidemiological studies. One reason may be that causes of death are not or poorly reported, especially in the so-called oldest-old people who are also the most affected by excess mortality. Deaths are often attributed to chronic diseases without information about triggering factors. As shown by Fedeli and colleagues in Italy, all causes of death (except cancer) have increased in 2015 , including circulatory diseases and neurologic/psychiatric diseases, and not only respiratory diseases and infectious diseases. Very few deaths are directly attributed to heat or cold. Most are attributed to the underlying morbidity that is decompensated by these triggering factors. On death certificates, almost no death is attributed to specific pollution episodes even if the World Health Organization attributes more than 7 million deaths annually to pollution. Santé publique France, for instance, estimated that fine particles cause 48,000 deaths per year in France; fine particles kill via respiratory failure or acute cardio-vascular diseases. The relative share of climatic factors, pollution episodes, influenza epidemics and other viruses in the excess mortality remains to be described and important questions stay unanswered. What is the proper contribution of each factor to excess mortality and what is the contribution of particular combinations of these factors? How could we disentangle direct and indirect effects, i.e. pathways involving the decompensation of chronic diseases [5], highly prevalent in old people?

These questions should be considered with respect to demographic changes resulting from the adult longevity revolution. The shift to higher ages of the center of distribution 
of the individual lifespans is currently literally exploding the numbers of nonagenarians and centenarians in the low mortality countries, as well as in Western Europe [6]. These new "survivors" are often very frail individuals, who may be the first victims of heat waves or influenza epidemics. As an example, a simulation work shows that the big heat wave of summer 2003, responsible for about 15,000 deaths in France in 10 days and 45,000 in Europe, would have done much more damage if it had occurred in 2016, simply because the number of people in the age groups who suffered the most from this heatwave, i.e., those over 80 years of age, had increased by $50 \%$ since 2003 . Conversely, if mild winters succeed fresh summers and vice versa, the mortality of the oldest old people can greatly diminish and inflate the population of very old people by the following January 1st; which apparently occurred in 2014 in Italy as Fedeli and his colleagues point out.

Their article concludes logically with a plea in favor of flu vaccination. Old people remain poorly vaccinated in Europe but effectiveness of vaccination is also known to decreases with age, whether it is due to immuno-senescence or to interactions with the common chronic comorbid conditions of the oldest-old people [7]. Furthermore, it should be noted that a large proportion of the oldest old people live in nursing homes and other collective households. For instance, in France, $34 \%$ of female nonagenarians and $56 \%$ of female centenarians are living in nursing homes according to the 2013 census. The number of nonagenarians and centenarians is expected to increase tremendously in the coming decades, the current figures of 464,330 female nonagenarians and centenarians being multiplied by 4 in 50 years according to the central scenario of the French forecasts. One cannot be satisfied with such a situation and the new call of the Innovative Medicines Initiative 2 (IMI 2), which is about analyzing the infectious disease burden and the use of vaccines to improve healthy life years in aging populations, is more than welcomed. Aging Clinical and Experimental Research will obviously be very interested in the results of this program. Aging Clinical and Experimental Research should also consider to publish more work on the role of environmental factors because the revolution of adult longevity is leading to an accumulation of very old people presenting an increased vulnerability to environmental stresses [8]. For all these reasons, gerontology journals should play a central role in the publication of work on the effect that environmental factors can have on health.

\section{Compliance with ethical standards}

Conflict of interest On behalf of all authors, the corresponding author states that there is no conflict of interest.

\section{References}

1. Fedeli U, Capodaglio G, Schievano E, Ferroni E, Corti MC (2017) Excess mortality in 2015: a time series and cause-of-death analysis in Northern Italy. Aging Clin Exp Res. doi:10.1007/ s40520-017-0773-0

2. Mazick A, Gergonne B, Nielsen J et al (2012) Excess mortality among the elderly in 12 European Country, February and March 2012. Eurosurveillance 17(14). http://www.eurosurveillance.org/ content/10.2807/ese.17.14.20138-en. Accessed 16 Oct 2017

3. Mølbak K, Espenhain L, Nielsen J et al (2015) Excess mortality among the elderly in European Country, December 2014 to February 2015. Eurosurveillance 20(11). http://www.eurosurveillance. org/content/10.2807/1560-7917.ES2015.20.11.21065. Accessed 16 Oct 2017

4. Staddon PL, Montgomery HE, Depledge MH (2014) Climate warming will not decrease winter mortality. Nat Clim Change 4:190-194

5. Maclityre CR, Mahimbo A, Moa AM, Barnes M (2016) Influenza vaccine as a coronary intervention for prevention of myocardial infarction. Heart 102:1953-1956

6. Robine JM, Cubaynes S (2017) Worldwide demography of centenarians. Mech Ageing Dev. doi:10.1016/j.mad.2017.03.004 [Epub ahead of print]

7. Lang P0, Mendes A, Socquet J, Assir N, Govind S, Aspinall $R$ (2012) Effectiveness of influenza vaccine in aging and older adults: comprehensive analysis of the evidence. Clin Interv Aging 7:55-64

8. Herr M, Arvieu JJ, Robine JM, Ankri J (2016) Health, frailty and disability after ninety: results of an observational study in France. Arch Gerontol Geriatr. 66:166-75. doi:10.1016/j. archger.2016.06.002 